\title{
Microstructural characteristics of electrodeposited damascene copper lines
}

\author{
T. N. Konkova ${ }^{1,2 \dagger}$, S. Yu. Mironov ${ }^{3}$, Y. Ke ${ }^{2}$, J. Onuki ${ }^{2}$ \\ †konkova_05@mail.ru \\ ${ }^{1}$ Institute for Metals Superplasticity Problems RAS, Khalturin St. 39, 450001, Ufa, Russia \\ ${ }^{2}$ Department of Materials Science and Engineering, Ibaraki University, Hitachi, Ibaraki 316-8511, Japan \\ ${ }^{3}$ Department of Materials Processing, Graduate School of Engineering, Tohoku University, 6-6-02 Aramaki-aza-Aoba, \\ Sendai 980-8579, Japan
}

The high-resolution electron backscatter diffraction technique and transmission electron microscopy were applied to study microstructure in the overburden layer, in upper and bottom parts of as-deposited as well as subsequently annealed nanoscale $\left(100 \mathrm{~nm}\right.$ width) copper wires. It was shown that the temperature interval $100^{\circ} \mathrm{C}-200^{\circ} \mathrm{C}$ should be seen as a transition period of microstructure evolution in damascene copper lines.

Keywords: copper, electrodeposition, EBSD, structure, texture.

\section{Introduction}

It is well known that there is a direct relationship between the structure and properties of materials. In case of interconnects the major attention is focused on resistivity-grain size dependence [1-23]. For manufacturing of such interconnects, a copper damascene process is currently used. Generally, it involves a preliminary deposition of a thin dielectric substrate, its subsequent etching to form a line pattern and final electrodeposition of copper to fill it up. Copper in excess, sometimes referred to as the overburden layer, is then removed using a chemical-mechanical polishing process. Modern electronic technologies require the reduction of interconnects widths down to nano-scale. However, the resistivity of the narrow copper lines increases considerably in the nano-scale range [1-2]. Despite significant industrial importance and considerable academic interest, microstructural observations in the nano-scale wires are still limited to a few examples [3-9]. It is important to emphasize that the analysis of nano-scale copper wires in most cases has been done on samples after annealing, including sufficiently detailed investigation [10,11], but, to the best of the authors' knowledge, there is no data about microstructure of nanoscale damascene copper lines before annealing, immediately after electrodeposition; in other words, data in present work are likely to be regarded as a novelty. This work presents an analysis of microstructure and texture in as-deposited copper wires as well as after annealing in an attempt to establish a better understanding of the grain-growth behaviour in these materials.

\section{Experimental procedure}

Damascene trenches (100 nm wide and $250 \mathrm{~nm}$ height) were patterned in $\mathrm{SiO}_{2} / \mathrm{Si}$ dielectric films using electron beam lithography and reactive ion etching. Experimental details you can find elsewhere [12]. To investigate the annealing behavior of the copper lines, electrodeposited specimens were annealed for $1 \mathrm{~h}$ at temperatures in the range from $100^{\circ} \mathrm{C}$ to $200^{\circ} \mathrm{C}$ in vacuum $\left(6.6 \times 10^{-3} \mathrm{~Pa}\right)$ immediately after completion of the electrodeposition process. All specimens were stored in vacuum chamber prior to microstructural examinations.

The microstructural examinations were performed using the electron backscatter diffraction (EBSD) technique on the longitudinal (i.e. LD-TD) plane and the STEM in crosssectional direction of copper interconnect (i.e. LD-ND). For EBSD analysis, a Hitachi ultra high resolution FE-SEM SU8240 field emission scanning electron microscope employing a novel cold field emission (CFE) gun equipped with an Oxford Instruments EBSD system as well as a Hitachi S-4300SE field emission gun scanning electron microscope equipped with a TSL OIM ${ }^{\mathrm{TM}} \mathrm{EBSD}$ system were employed. To evaluate the possible variations of microstructure and texture in the thickness direction, the observations were made at the trench heights of $\sim 80 \mathrm{~nm}$ and $\sim 240 \mathrm{~nm}$ (which corresponded to bottom and upper parts of the line, respectively) as well as in the overburden layer. Chemical mechanical polishing was applied to remove the excess copper and TaN/Ta layers from the trenches as well as to get the final surface finish for the EBSD observations.

The EBSD maps were acquired with a scan step size of $30 \mathrm{~nm}$ for as-deposited material in the overburden layer as well as for material after annealing at $200^{\circ} \mathrm{C}$; scan step size in other cases was $5 \mathrm{~nm}$. Due to the experimental accuracy limit of EBSD, a lower limit boundary misorientation cut-off of $2^{\circ}$ was used.

Due to lattice distortion and the fine nature of the microstructure, reliable EBSD maps could not be obtained from the overburden layer of as-deposited material as well as from the specimen annealed at $100^{\circ} \mathrm{C}$. In these cases, the 


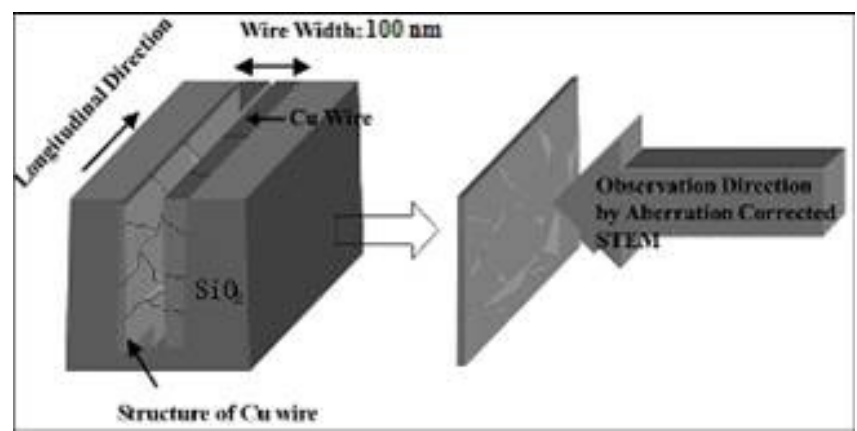

a

Fig. 1. Schematic drawings of (a) the structure of the $\mathrm{Cu}$ interconnect and (b) thinned sample for TEM-EDX observation. The samples were prepared by a highly sophisticated ion beam (FIB) technique.

EBSD data were used only for qualitative evaluation of the developed microstructure.

In addition to EBSD, aberration Corrected STEM analysis was used to investigate microstructure of as-deposited copper wire (before annealing). For that purpose, thin sample was cut from the copper interconnect by using micro sampling method as shown in fig.1, and aberration Corrected STEM analyzes in the cross-sectional direction of $100 \mathrm{~nm}$ wide copper interconnects were done using Hitachi $300 \mathrm{kV}$ HR-STEM equipped with EDX (Energy Dispersive X-ray Spectroscophy) analyzer.

\section{Results}

\section{Microstructure}

A cross-sectional aberration corrected STEM micrograph of the structure of the as-deposited (before annealing) copper interconnects is presented in fig.2.

STEM observations revealed fine grain nature of the microstructure, as seen in fig.2. Normally, there are 3-4 grains spanned across the line height. Considering the height of the trench $(\sim 250 \mathrm{~nm})$, the average grain size seems to be $\sim 60-80 \mathrm{~nm}$. However, it is important to emphasize that the microstructure is inhomogeneous in the vertical direction. Microstructure in the upper part of the lines seems to be relatively coarse grained $(\sim 150-200 \mathrm{~nm})$. One of the possible explanations for this effect is downward penetration of the growing grains from the overburden layer [10,11]. As follows from variation of the STEM contrast as well as from the presence of thin extinction contours, the material is characterized by large internal stresses. Surprisingly, dislocation density was found to be relatively low. Sporadic twins were also found in the microstructure. The twins are thought to originate from room temperature annealing of as-deposited material before microstructural investigation.

The overburden layer in the as-deposited- as well as in the annealed at $100^{\circ} \mathrm{C}$ states was comprised by fine elongated grains with a longitudinal size of $\sim 200-300 \mathrm{~nm}$. There were also isolated, relatively coarse $(\sim 1 \mu \mathrm{m})$ grains containing annealing twins in the microstructure. In the bottom part of the lines, the as-deposited microstructure was bimodal, characterized by the presence of relatively coarse $\sim 70 \mathrm{~nm}$ grains, as well as $\sim 20 \mathrm{~nm}$ grains. It is important to emphasize that grains were essentially equiaxed in both cases. The

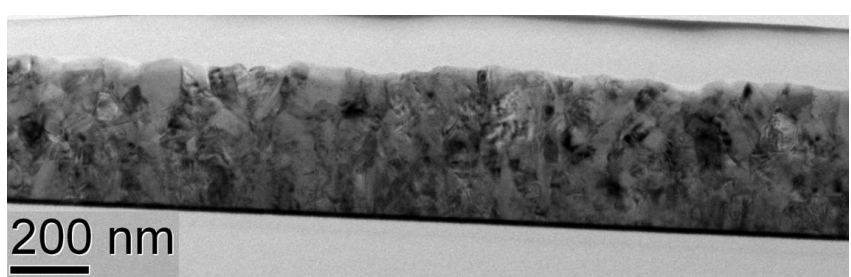

a

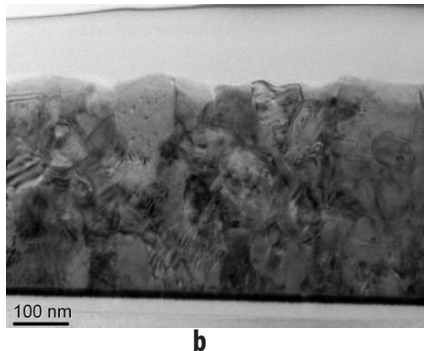

Fig. 2. A cross-sectional aberration corrected STEM micrograph of the structure of the copper interconnects: (a) low magnification, (b) large magnification.

observed grains spanning across the total line width in the bottom part of the lines, i.e. the copper wires were only one grain in width; it was thought to be related to the nucleation of grains at the trench bottom surface.

In contrast to the microstructure in bottom part of the lines, the upper part was characterized by presence of two grains in line width normally located close to wire's walls. In this regard, it may be hypothesized grain nucleation at the sidewalls of trenches followed by their growth towards each other up to their «meeting».

Interesting to note that the annealing at $100^{\circ} \mathrm{C}$ did not led to substantial changes either in upper or bottom part of the lines. The microstructure in bottom part also was characterized by presence one large $(\sim 60 \mathrm{~nm})$ grain spanning across the total line width as well as some small $(\sim 11 \mathrm{~nm})$ grains. Upper part of lines was characterized by presence of two grains in line width located close to the sidewalls.

Selected portions of the EBSD maps illustrating the microstructure after annealing at $200^{\circ} \mathrm{C}$ in different parts of the damascene lines are shown in fig.3. Grains are colored according to their crystallographic orientations relative to the $\mathrm{ND}$ (a color code triangle is given in the figure).

Annealing at $200^{\circ} \mathrm{C}$ led to significant microstructural changes in the overburden layer in very narrow copper wires [11] (fig.3). The microstructure substantially coarsened achieving a typical grain size of $\sim 2 \mu \mathrm{m}$, the grains became essentially equiaxed and typically contained annealing twins (an example is indicated by the arrow in fig.3a). The microstructure developed after annealing at $200^{\circ} \mathrm{C}$ did not contain abnormal coarse grains thus indicating that the grain growth was reasonably homogeneous.

In contrast to the as-deposited state as well as the material annealed at $100^{\circ} \mathrm{C}$, the microstructure of the $200^{\circ} \mathrm{C}$ annealed samples was characterized by bamboo-type grains spanning across the line width (figs.3b-c) with a typical grain size of $\sim 0.2 \mu \mathrm{m}$.

In other words, the above data evidence significant microstructural changes after annealing at $200^{\circ} \mathrm{C}$. It may be hypothesized that this temperature is a transition temperature for microstructure evolution and therefore it is required an additional investigation. 

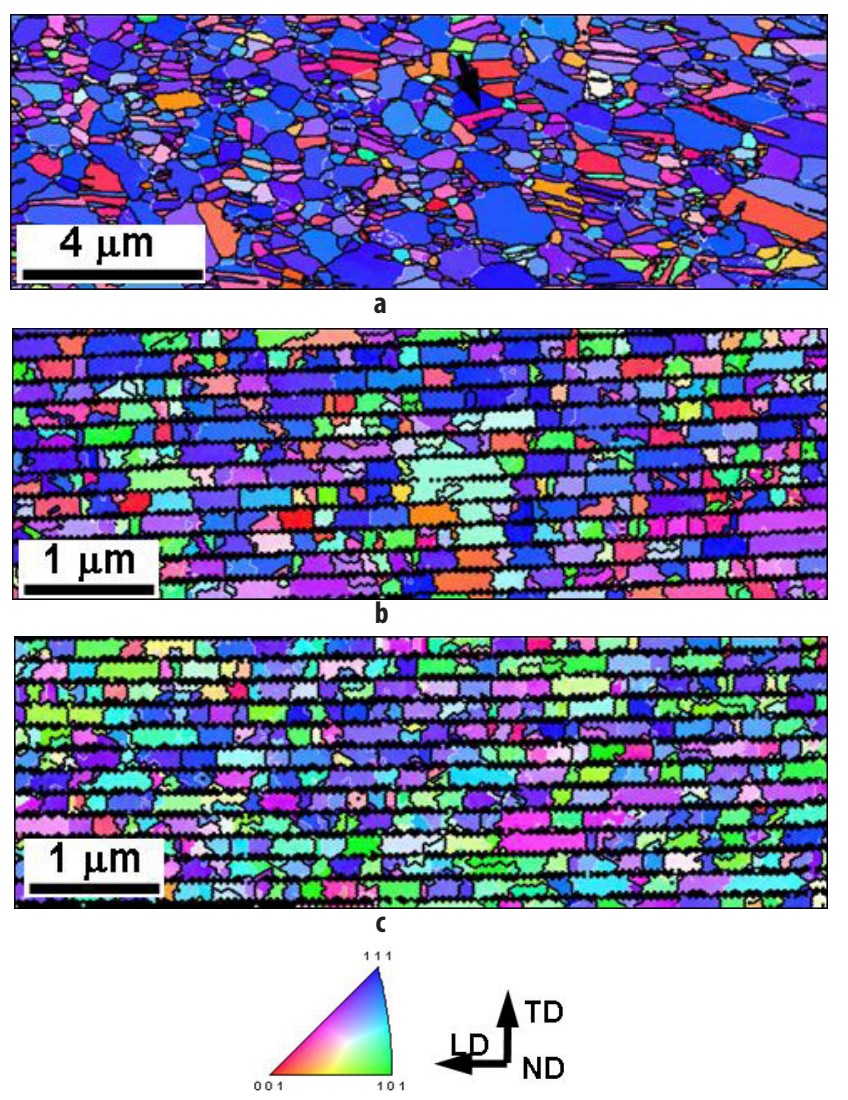

Fig. 3. EBSD maps illustrating grain structure in the overburden layer (a), upper (b) and bottom (c) parts of the damascene copper lines annealed at $200^{\circ} \mathrm{C}$. In the maps, grains are colored according to their crystallographic orientations relative to the ND (color code triangle is shown on figure).

\section{Texture}

The 111 and 110 pole figures illustrating effect of annealing temperature on textural changes in the overburden layer, upper and bottom parts of the lines after annealing at $200^{\circ} \mathrm{C}$ are summarized in fig.4. Usually, these textures were found to contain several textural components which were characterized by the strongest intensity in the pole figures.

In the overburden layer of sample after annealing at $200^{\circ} \mathrm{C}$ a $<111>/ / N D$ fiber texture was found to predominate (fig.4a). The formation of such texture indicated an alignment of the close packed $\{111\}$ planes with substrate surface. This texture is often observed in deposited copper films and commonly attributed to minimization of surface energy $[22,23]$. It was also noteworthy that this texture component notably strengthened with annealing temperature [11]. The material of the overburden layer also contained a minor fraction of $<100>/ /$ ND fiber texture, which was typically associated with annealing twins in the $<111>$ grains.

The texture developed in the upper part of the lines (fig.4b) might be described in terms of the superposition of the $\{111\}$ $<110>$ sidewall texture component and the $<111>/ / N D$ fiber texture. The formation of the $\{111\}<110>$ component in this region is well documented and is usually related with grain nucleation at the sidewalls of trenches [13,14]. In this case $\{111\}$ plane should be aligned with substrate surface, which is seen after annealing at $200^{\circ} \mathrm{C}$. The presence of the $<111>$-fiber texture in upper part of the trench was difficult to explain from the nucleation standpoint. It seemed reasonable to
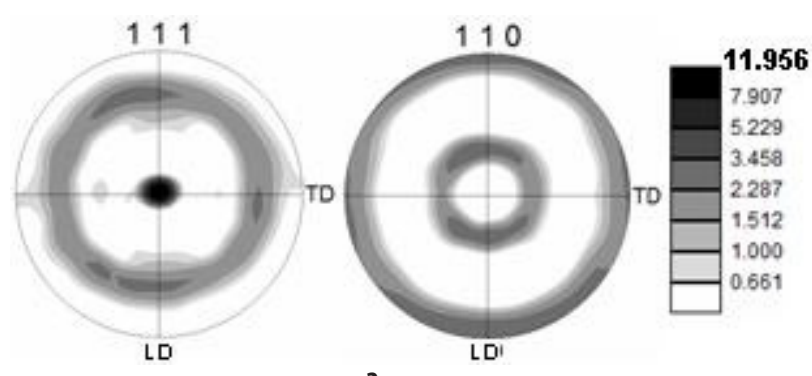

111
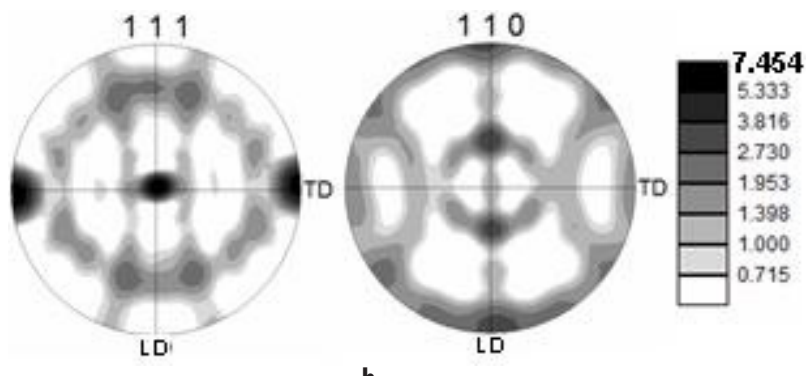

b
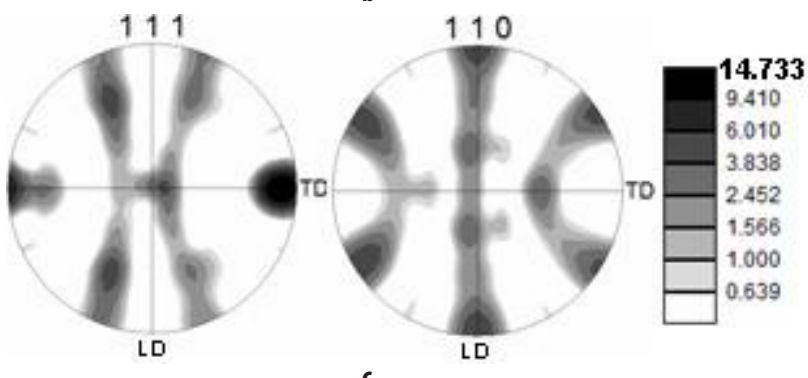

Fig. 4. 111 and 110 pole figures illustrating effect of annealing temperature on texture evolution in the overburden layer (a), upper (b) and bottom (c) parts of lines after annealing at $200^{\circ} \mathrm{C}$.

hypothesize in this regard that this texture originated from the penetration of the growing grains from the overburden layer. This idea is in agreement with the current conception of the grain growth in the narrow damascene copper lines [15-17].

In the bottom part of the line the samples are characterized by the texture mainly consisted of the sidewall as well as outof-plane $\{111\}<110>$ texture components (fig.4c). The latter orientation was attributable to nucleation of grains at the trench bottom surface [18-21]. Both components were as expected in this region. However, the observed pronounced strengthening of the out-of-plane texture with temperature [11] presumably indicated growth of the bottom grains. If so, the vertical grain growth in the lines involved not only downward penetration of the overburden grains but also upward propagation of the bottom grains.

\section{Conclusions}

In this work the structural features of as-deposited nanoscale damascene copper lines as well as material after annealing at $100^{\circ} \mathrm{C}-200^{\circ} \mathrm{C}$ were studied. Microstructural and textural changes were tracked in the overburden layer as well as in the upper and bottom parts of the lines. The features of microstructure in as-deposited (without annealing) nanoscale copper wires have never been studied before. The main conclusions are as follows.

The structural and textural observations revealed some evidence of downward penetration of the growing grains 
from the overburden layer in upper part of lines as well as grain nucleation on the bottom trench surface.

Large difference in structure characteristics between material after annealing at $100^{\circ} \mathrm{C}$ and $200^{\circ} \mathrm{C}$ has been interpreted as evidence that this temperature interval should be seen as a transition period of microstructure evolution in damascene copper lines.

Financial support from Grants-in-aid for Science Research (Contract Nos. 17206071 and 20226014) and from JST is gratefully acknowledged. The authors are very grateful to Nippon of Metal Co., Ltd. for supplying the high purity electroplating solution and ultrahigh purity anode copper plate; to Hitachi High-Tech for provision of FE-SEM SU8240. They also would like to thank Mr. T. Namekawa for technical assistance.

\section{References}

1. W. Steinhogl, G. Schindler, G. Steinlesberger, M. Traving, M. Engelhardt. J. Appl. Phys. 97 (2005) 023706.

2. V. Carreau, S. Maîtrejean, M. Verdier, Y. Bréchet, A. Roule, A. Toffoli, V. Delaye, G. Passemard. Microelectron. Eng. 84, 2723 (2007).

3. S. Brandsetter, V. Carreau, S. Maitrejean, M. Verdier, M. Legros. Microelectronic Engineering. 87, 383 (2010).

4. S. Brandsetter, E. F. Rauch, V. Carreau, S. Maitrejean, M. Verdier, M. Legros. Scripta Materialia. 63, 965 (2010).

5. J. Onuki, K. Khoo, Y. Sasajima, Y. Chonan, and T. Kimura. J. Appl. Phys. 108, 044302 (2010).

6. K. Khoo, J. Onuki. Thin Solid Films. 518, 3413 (2010).

7. J. Onuki, S. Tashiro, K. Khoo, N. Ishikawa, T. Kimura, Y. Chonan, and H. Akahoshi. J. Electrochem. Soc. 157, 857 (2010)

8. T. Inami, J. Onuki, and M. Isshiki. Electrochemical and Solid-state Letters. 14, 1 (2011).
9. K. J. Ganesh, A.D. Darbal, S. Rajasekhara, G.S. Rohrer, K. Barmak and P. J. Ferreira. Nanotechnology. 23, 1 (2012).

10. Y. Ke, T. Konkova, S. Mironov, K. Tamahashi, J. Onuki. Thin Solid Films. 539, 207 (2013).

11. T. Konkova, S. Mironov, Y. Ke, J. Onuki. Electrochemistry. 81, 616 (2013).

12. Y. Ke, T. Konkova, S. Mironov, J. Onuki. Letters on materials. 2, 198 (2012).

13. J.-Y. Cho, H.-J. Lee, H. Kim, J.A. Szpunar. Archives of Metallurgy and Materials. 50, 261 (2005).

14. J.-Y. Cho, H.-J. Lee, H. Kim, and J. A. Szpunar. Journal of Electronic Materials. 34, 506 (2005).

15. S.H. Brongersma, E. Kerr, I. Vervoort, A. Saerens, K. Maex. J. Mater. Res. 17, 582 (2002).

16. W. Wu, D. Ernur, S.H. Brongersma, M. Van Hove, K. Maex. Microelectronic Engineering. 76, 190 (2004).

17. W. Zhang, S.H. Brongersma, N. Heylen, G. Beyer, W. Vandervorst, and K. Maex. Journal of The Electrochemical Society. 152, 832 (2005).

18. T. Muppidi, D. P. Field, J. E. Sanchez Jr., C. Woo. Thin Solid Films. 471, 63 (2005).

19. J.-Y. Cho, K. Mirpuri, D. N. Lee, J.-K. An and J. A. Szpunar. Journal of Electronic Materials. 34, 53 (2005).

20. J.-Y. Cho, H.-J. Lee, H. Kim, J.A. Szpunar. Archives of Metallurgy and Materials. 50, 261 (2005).

21. H. J. Lee, H. N. Han, and D. N. Lee. Journal of Electronic Materials. 34, 1493 (2005).

22. D. P. Field, O. V. Kononenko, and V. N. Matveev. Journal of Electronic Materials. 31, 40 (2002).

23. N.-J. Park, D.P. Field, M. M. Nowell, and P. R. Besser. Journal of Electronic Materials. 34, 1500 (2005). 